\title{
Análise comparativa das propostas cariocas e baiana para a regulamentação desportiva da capoeira (1968)
}

\section{Ana Rosa JAQUEIRA* \& Paulo Coêlho de ARAÚJO}

Universidade de Coimbra (Portugal)

Recepción: 13/08/2012; Aceptación: 17/10/2012; Publicación: 10/01/2013.

\begin{abstract}
Resumo
Antecedentes e objetivos: Apesar de ter sido institucionalizada na Confederação Brasileira de Pugilismo (1941) como desporto, a Capoeira ainda não tinha regulamento de competição. A realização de dois simpósios (1968 e 1969) no Rio de Janeiro (Guanabara) buscou a regulamentação da expressão e consequente promoção da igualdade de condições aos atletas competidores. Para tanto foram convidados ao diálogo seus representantes oriundos da Bahia e do Rio de Janeiro. 0 presente estudo analisa as primeiras propostas de regulamentação da Capoeira, provenientes dos Estados da Bahia e do Rio de Janeiro e apresentadas no simpósio de 1968.

Método: Foram utilizados os métodos etnográfico e histórico, análise de conteúdo, análise praxiológica e entrevistas semiestruturadas para o levantamento, tratamento e interpretação dos dados e posterior comparação das propostas.

Resultados: Observamos que a proposta baiana foi caracterizada por elementos gímnicos, lúdicos e rituais, ao passo que as cariocas se caracterizaram pelo aspecto agonístico da modalidade. Fatores personalísticos, estilísticos e territoriais interferiram sobejamente para a não consecução do regulamento desportivo da luta da Capoeira, do que concluímos que não estavam reunidas naquele momento as condições ideais para a regulamentação da Capoeira.
\end{abstract}

Palavras-chave: Capoeira, luta, Brasil, regulamentação desportiva, praxiologia motriz.

\section{Comparative analysis of the proposals from Rio de Janeiro and Bahia for the sporting regulation of capoeira (1968)}

\begin{abstract}
Background and aim: Despite having been institutionalised in the Brazilian Confederation of Pugilism (1941) as a sport, at that time there were not any regulations for Capoeira competitions. Two symposia (1968 and 1969) were held in Rio de Janeiro (Guanabara) aiming to establish a set of regulations for the discipline and, as a consequence, to provide equal conditions for the competing athletes. In order to do so, representatives from Bahia and Rio de Janeiro were invited to discuss the matter. The present study analyses the first three proposals for the regulation of Capoeira, which came from the states of Bahia and Rio de Janeiro and were presented at the symposium held in 1968.

Method: The ethnographic and historical methods were used along with content analysis, praxeological analysis and semi-structured interviews for the survey, processing and interpretation of data, and subsequent comparison of the proposals.

Results: We observed that the proposal from Bahia was characterised by gymnastic, recreational and ritual elements, whereas those from Rio de Janeiro were characterised by the agonistic aspect of the discipline.
\end{abstract}

Análisis comparativo de las propuestas carioca y bahiana para la reglamentación deportiva de la capoeira (1968)

\section{Resumen}

Antecedentes y objetivo: A pesar de haber sido institucionalizada en la Confederação Brasileira de Pugilismo (1941) como deporte, la capoeira aún no tenía reglamento de competición. La realización de los simposios (1968 y 1969) en Río de Janeiro (Guanabara) buscó establecer un conjunto de reglas para la disciplina, y consecuentemente lograr la igualdad de condiciones de los competidores. Para ello se invitó a debatir a los representantes de Bahía y de Río de Janeiro. El presente estudio analiza las primeras propuestas de reglamentación de la capoeira, realizadas por representantes oriundos de los estados de Bahía y de Río de Janeiro y presentadas en el simposio de 1968.

Método: Se utilizó el método etnográfico y el método histórico, análisis de contenido, análisis praxiológico y entrevistas semiestructuradas para la recogida, tratamiento e interpretación de los datos, y la subsiguiente comparación de propuestas.

Resultados: Observamos que la propuesta bahiana se caracterizó por elementos gimnásticos, lúdicos y rituales, mientras que la carioca se caracterizó por el aspecto agonístico de la modalidad. Factores personales,

*E-mail: anarosa@fcdef.uc.pt. Dirección: Faculdade de Ciências do Desporto e Educação Física. Universidade de Coimbra. Estádio Universitário, Pavilhão 3. 3040-156. Coimbra (Portugal). 
Differences regarding personal and stylistic views and territorial interests proved to be a major hindrance and no regulations were established. Therefore, we conclude that the ideal conditions for the sporting regulation of Capoeira could not be met at that time.

Keywords: Capoeira, figth, Brazil, sporting regulation, motor praxeology. estilísticos y territoriales supusieron los mayores obstáculos parar la no consecución de un reglamento deportivo de la capoeira, de lo que se concluye que en aquel momento no existían las condiciones ideales para lograr la reglamentación deportiva de la capoeira.

Palabras clave: Capoeira, lucha, Brasil, reglamentación deportiva, praxiología motriz.

\section{1.- Introdução}

A capoeira, enquanto modalidade de luta, vem sofrendo transformações ao longo da sua história que a tornaram multifacetada. A esse continuum Araújo (2007, p. 199) chamou de "múltiplas transformações", considerando o seu aparecimento enquanto luta e as suas metamorfoses, concomitantes ou não, em defesa pessoal, jogo e desporto.

O processo de transformação da capoeira em desporto, ou a sua desportivização, é um fenômeno recente e contextualiza a temática deste estudo: a regulamentação da luta brasileira. Entre o que Elias (1992, p. 224) considerou como sintoma da configuração desportiva estão: a criação de espaços especializados para a sua prática, o desenvolvimento de uma temporalidade ou formas de organização, a anulação das diferenças sociais em favor da igualdade de oportunidades, a imposição de uma ética de lealdade e a estandardização das regras.

Assim sendo, buscaremos tratar de um dos aspectos do processo da transformação da capoeira em desporto - as propostas para a sua regulamentação desportiva como luta considerando como marcos teóricos dessa abordagem comparativa as "múltiplas transformações" em sua fase terminal, a desportiva, e a Praxiologia Motriz (Parlebas, 2001, p. 354), enquanto instrumento de confrontação das propostas cariocas e baiana, e posterior extração de seus principais enfoques.

A transformação da capoeira em desporto foi influenciada por alterações nos cenários político, social, jurídico e desportivo brasileiros, dos quais ressaltamos, respectivamente: a ideologia da identidade nacional vigente no governo de Getúlio Vargas (1930 a 1945), continuada no período do governo militar, o que facilitou a difusão da capoeira pela coletividade brasileira e coincidiu com a sua descriminalização através da sua não inclusão ou não citação na nova redação do Código Penal Brasileiro; a influência da criação do Conselho Nacional de Desporto (CND), via Decreto-Lei no 3.199, de 1941 (Lardies, 1964, p. 27); e a instalação da capoeira no seio da Confederação Brasileira de Pugilismo (CBP), em 1941, fato que confirmava o desiderato da cristalização da sua faceta original de luta.

Especificamente no cenário desportivo brasileiro encontramos a publicação da Deliberação no 71/53 do Ministério da Educação e Saúde (Lardies, 1964, p. 155), que permitiu, a título de experiência, o funcionamento de centros de instrução pugilística, sendo nela referida pela primeira vez a modalidade capoeira. Em 1962 o Estatuto da Confederação Brasileira de Pugilismo (CBP) reconhece o Jiu-Jítsu e a capoeiragem como atividades pró-desporto, ou seja, em vias de regulamentação até se enquadrarem no modelo desportivo especializado conceitualmente concebido, "admitindo-se lutas dessas especialidades" no contexto da organização interna dessa federação através dos seus Departamentos Especiais (DEC).

No âmbito da própria modalidade, acontecimentos como a autorização e registro para o funcionamento do Curso de Educação Physica do Mestre Bimba (1937) em sua escola ou academia (Rego, 1968, p. 287) e a criação do Centro Esportivo de Capoeira Angola (1941), do Mestre Pastinha (Idem, p. 283), influenciaram sobejamente a sua afirmação enquanto desporto.

Das federações afiliadas à Confederação Brasileira de Pugilismo (CBP), foi a Federação Carioca de Pugilismo (Guanabara / Rio de Janeiro) aquela que nos anos 60 do século XX se dispôs a controlar as atividades da Capoeira ${ }^{1}$ enquanto manifestação desportiva, compreendendo a

1 Ofício da Confederação Brasileira de Pugilismo - CBP 1542/68: Simpósio de Capoeira: convite, a 16/08/1968. 
necessidade de se iniciar um processo abrangente e estruturado visando a sua regulamentação, e nesse sentido promoveu um simpósio no ano de 1968 e outro em 1969.

Se considerarmos ser o estado da Bahia o mais representativo dessa modalidade nesse período, reflexo instintivo de preservação de um elemento de cultura popular, a localização das iniciativas de regulamentação da capoeira no Rio de Janeiro parece a princípio curiosa. A preponderância da capoeira praticada na Bahia sobre os outros estados brasileiros é particulamente notada tendo-se em conta a tradição oral que refere a luta, contrariamente à tradição escrita existente e pertinente à capoeira praticada no Rio de Janeiro, compulsada para a consecução deste estudo.

Essa lacuna deixada por parte da Federação Baiana de Pugilismo (FBP) na via da regulamentação desportiva da capoeira nos permite visualizar o quadro das tendências da luta brasileira nos níveis territorial, estilístico, personalístico e da dinâmica cultural da sua rede configuracional. A autoconfiguração dos capoeiristas em grupos variados de variadas estilísticas, bem como a assunção do controle do desenvolvimento da prática por parte de lideranças reconhecidas, demonstrava que era assumida naquele estado uma posição de certa naturalidade perante as circunstâncias.

Vale salientar que a falta de iniciativa do órgão federativo do estado da Bahia quanto ao movimento de regulamentação da capoeira e, consequentemente, dos seus praticantes, em grupo ou isoladamente, decorre da hegemonia das posições das lideranças da capoeira baiana do período, os mestres Bimba e Pastinha, que consideravam que essa expressão de luta não se adequava aos combates com regulamentações ou juízes (Jornal A Tarde, 1969, novembro 17).

Acreditamos que a localização da Confederação Brasileira de Pugilismo (CBP) e da sede do Conselho Nacional de Desportos (CND) na cidade do Rio de Janeiro pode ter propiciado à Federação Carioca de Pugilismo (FCP) a iniciativa de se pronunciar como precursora da organização das regras de competição da capoeira desportiva.

Não obstante, o desenvolvimento do desporto em geral e das federações componentes da eclética Confederação Brasileira de Pugilismo (CBP) também era fator preponderantemente favorável à consecução do desafio que se apresentava, o de regular o desporto considerado de identidade nacional já presente no ideário do Estado Novo e no contexto político pós-1964, com vista à cooptação das lideranças de expressões populares, entre elas a capoeira.

Todavia, mesmo concentrados os esforços de pessoas ligadas à capoeira ou a outras lutas desenvolvidas no Brasil, partilhando ou não o pensamento político da época, o certo é que a regulamentação da luta brasileira não se consumou naquele momento em virtude da falta de consenso entre baianos (Angola e Regional) e cariocas (capoeira de Sinhozinho e representantes da CBP), confirmando o objetivo através dos documentos relativos ao assunto em pauta. Também não se consumou o pretendido pela política de cooptação das lideranças em nível nacional, ou seja, o controle dos grupamentos de pessoas praticantes da modalidade, auto-organizadas em grupos de capoeira, disseminados pelo Brasil.

A realização do I e II Simpósio de Capoeira, dirigidos aos interessados no processo de regulamentação desportiva da modalidade, capoeiristas ou não, visava, conforme diz o Ofício da CBP no 1.542/68, de 16 de agosto de 1960, a "uniformização das escolas ou estilos de capoeira da Bahia e da Guanabara, incontestavelmente os dois mais adiantados e difundidos do País", bem como a homogeneização/harmonização da sua linguagem desportiva nos níveis nacional e internacional.

A indicação limitada das escolas ou estilos dos estados referidos sugere o reconhecimento apenas da Capoeira Regional Baiana, por sua difusão nacional e pelo carisma de seu mentor, o Mestre Bimba, e da capoeira desenvolvida pelo Mestre Sinhozinho no estado da Guanabara (Rio de Janeiro).

Todavia, desse estado surgiu mais uma proposta de regulamentação da capoeira, naturalmente oriunda dos seus admiradores que integravam o organograma da CBP, órgão no qual estavam instaladas pessoas ligadas ao ramo pugilístico por meio de modalidades já organizadas e regulamentadas desportivamente. 
A desconsideração, por parte dos idealizadores dos simpósios, de outros estilos ou escolas de capoeira relacionados por autores/escritores (Mário Aleixo, Burlamaqui e Inezil Penna Marinho) à altura das três primeiras décadas do século XX já indiciava dois aspectos relevantes da problemática da organização da capoeira no que toca à sua regulamentação desportiva.

Por um lado, a supremacia do estilo de Bimba, a dificuldade em lapidá-lo e harmonizá-lo conforme ocorrera nas histórias de lutas estrangeiras já disseminadas socialmente e a centralização do estado carioca diante da capoeira do Recife, por exemplo, fartamente propalada pelos folcloristas pernambucanos; por outro, os problemas das visões dos idealizadores dos simpósios, conhecedores ou praticantes de lutas notoriamente organizadas e regulamentadas, problemas esses que se traduziriam pela força das individualidades diante do irreversível fenômeno de transformação em desporto que abarcava a luta brasileira.

\section{2.- Objetivos e justificativa}

Este trabalho teve como objetivos analisar, interpretar e caracterizar as primeiras propostas de regulamentação para a competição da capoeira na perspectiva da luta, justificando-se pela inexistência de outras investigações que interpretem, caracterizem e registrem a história regulamentar desportiva da modalidade, o que demanda, fundamentalmente, a análise de fontes primárias relativas ao processo da transformação em desporto dessa modalidade de luta essencialmente brasileira, nunca antes consultadas para fins de construção de uma parte da história do desporto no Brasil, em geral, e da capoeira, em particular.

\section{3.- Metodologia}

Optamos por utilizar um processo multimétodos, considerando o método etnográfico e o método histórico.

A opção pelo método etnográfico no contexto deste estudo deve-se ao seu caráter inicial descritivo (Baztán, 1995, p. 4) e à possibilidade de utilização de múltiplas fontes de informação que essa metodologia de investigação permite (Hammersley \& Atkinson, 1994, p. 39).

Para responder a essa demanda, foi realizada análise bibliográfica pertinente ao assunto da regulamentação desportiva do desporto e da capoeira, tanto em conteúdo como em delimitação temporal, ou seja, o período em que a modalidade se encontrava inserida no âmbito da CBP; análise documental de fontes primárias e secundárias, destacando-se convites institucionais, cartas pessoais, ofícios, relatórios e notícias de jornais; e estudo de campo, por meio de entrevista semiestruturada com distintos personagens envolvidos direta e indiretamente nos simpósios realizados nos anos de 1968 e 1969, ou que deles tiveram conhecimento ulteriormente.

As referidas entrevistas foram pautadas por um rol de assuntos muito mais abrangentes do que apenas o que sustenta este artigo e permitiam aos entrevistados fixarem-se nos tópicos que mais lhes parecessem relevantes. Pode-se depreender da fala dos que tinham ${ }^{2}$ algum contributo a dar sobre o assunto que, já naquela época, existia certo processo de territorialização da expressão (Jaqueira, 2010), enquanto signo de qualidade ou de aceitação social, em função de uma característica estilística (Regional, Angola, Sinhozinho) ou geográfica (Bahia, Rio de Janeiro, São Paulo), ou ainda personalística (Bimba, Pastinha, Sinhozinho). Entre os entrevistados, destacam-se: o Dr. Decânio (A. Decânio, entrevista pessoal, agosto, 2003), assessor especial do DEC/Ba e representante da capoeira Regional do mestre Bimba; Rudolf Hermanny (R. Hermanny, entrevista pessoal, agosto, 2003), representante da capoeira do Rio de Janeiro e da capoeira do Sinhozinho; Lamartine Pereira da Costa (L. P. Costa, entrevista pessoal, agosto, 2003), assessor especial do DEC; e André Luiz Lacé Lopes (A. L. L. Lopes, entrevista pessoal, agosto 2004), assessor especial do DEC para o ano de 1974.

\footnotetext{
2 Lamartine Pereira da Costa apenas contribui com uma palestra no simpósio de 1969, e Mestre Ângelo Decânio, em vista da avançada idade, não se recordava de detalhes relativos aos simpósios, dos quais participou ativamente. Todavia, confirmou o aspecto da territorialização da Capoeira, sendo, portanto, relevante a documentação escrita compulsada.
} 
Com objetivos etnológicos, procedemos à análise de conteúdo de materiais volumosos (Albarello, L. Digneffe, F., Hiernaux, J-P., Maroy, C., Ruquoy, D., Saint-Jorges, P., 1997, p. 180) por meio da condensação descritiva e consequente indexação das fontes primárias (regulamentos, leis, decretos, jornais, convites, pareceres, cartas, entre outras), via categorias estabelecidas $a$ priori e $a$ posteriori (Franco, 2003, p. 52) e posterior análise comparativa entre os documentos-base deste estudo, as três propostas para a regulamentação desportiva da luta da capoeira, em seus aspectos fundamentais.

Foi realizada a análise praxiológica do conteúdo dessas propostas (Lagardera \& Lavega, 2003, p. 37) de forma a identificar elementos representativos das lógicas externa e interna da luta brasileira e posteriormente, consagrá-los coerentemente às formas de expressão referidas no material em causa, consoante às múltiplas transformações da capoeira (Araújo, 2007, p. 199): arte, jogo e desporto.

A opção pela utilização do método histórico decorre da sua qualidade essencial (Lalande, 1926/1993) - seu espírito crítico -, que permeou toda a realização das análises neste estudo, a iniciar por sua fase heurística, conforme a investigação dos acontecimentos e processos do passado, influenciados pelo contexto cultural particular da época (Lakatos \& Marconi, 1992, p. 83). Aqui se considera o fenômeno no ambiente social em que nasceu, o seu desenvolvimento e alterações, de forma a preencher o vazio dos fatos históricos sobre o processo da regulamentação desportiva da capoeira. Apoia-se em um tempo construído artificialmente de modo a promover a compreensão do seu continuum e o entrelaçamento dos fenômenos conforme o âmbito de investigação (Cohen \& Manion, 2002, p. 78): um indivíduo, um grupo, um movimento, uma idéia ou uma instituição, os quais não podem ser considerados isoladamente.

\section{4.- 0 estado das idéias e os discursos à época das propostas de regulamentação da capoeira}

No panorama do desenvolvimento desportivo desta modalidade à época da sua regulamentação, inferimos, através da análise das entrevistas, existir o fenômeno da territorialização da capoeira (Jaqueira, 2010), no que diz respeito à sua qualidade ou à sua aceitação social, de acordo com o "estilo" (Regional, Angola, Sinhozinho), a sua localização geográfica (Bahia, Rio de Janeiro, São Paulo), ou ainda personalística (Bimba, Pastinha, Sinhozinho).

A resistência dos praticantes da capoeira baiana à regulamentação da modalidade como luta resultava do seu desconhecimento do modelo desportivo. Desejavam regulamentar a expressão nos moldes praticados por eles, sem refletirem sobre a necessidade de uma reestruturação e harmonização dos padrões por eles instituídos em seus estilos de prática.

A análise de um significativo número de documentos que antecederam a realização dos simpósios, entre os quais se destacam os convites institucionais, cartas pessoais, ofícios, relatórios (Confederação Brasileira de Pugilismo, 1969) e notícias de jornais, revela que se estabelecia então um conflito idiossincrático.

Sobre o que se coloca, podem-se ler os excertos das notícias veiculadas pelos jornais $A$ Tarde e Diário Popular, destacando-se referências emitidas pelo Mestre Bimba ao retirar-se do evento em "sinal de protesto pelo baixo nível e falta de expressividade dos debates" (Diário Popular, 1969 novembro 17). Ao considerar ter sido ele quem "iniciou o esporte no Brasil e o tornou socialmente aceito" (A Tarde, 1969 novembro 11), revela a concepção que tinha do conceito de desporto e da Capoeira Regional Baiana, que não era senão a velha prática da capoeira dotada de novo nome. Bimba também declarou: "Tinha muita gente que não entende nada de capoeira querendo bancar o professor, e ainda, por ser esta uma luta violenta, e, por isso, não quer nem pensar em regulamentações ou juizes", o que mostra que ele ignorava que outros praticantes da modalidade estavam trabalhando para a sua aceitação social.

Note-se que, exatamente por ser uma luta violenta, segundo Bimba, é que para a sua introdução no seio do desporto de competição era necessário regrá-la e assim tornar o seu nível de agressividade compatível ao aceitável socialmente, aspecto que a regulamentação desportiva da luta conferiria aos combates aspirados. A "pretensa evolução", aludida por Bimba ao desvalorizar a tentativa de regulamentação da capoeira (Diário Popular, op. cit), não faria "desparecer a capoeira 
que ele criou" e que ele considerava de sua propriedade - referia ter sido ele "quem inciou o esporte no Brasil" (A Tarde, op. cit) -, apenas a tornaria diferente, definida, delimitada como desporto de luta, podendo claramente coexistir com todos os outros modelos de capoeira encontrados no Brasil. Obviamente, ela deixaria de "pertencer" a alguns indivíduos e passaria ao controle de instituições governamentais.

Saliente-se que, o referido mestre baiano, reconhecia a capoeira como "desporto" e até mesmo já participara isoladamente ou em conjunto com os seus mais hábeis alunos de duelos com outros capoeiristas e lutadores de Luta-Livre, Catch-as-Catch-Can e Jiu-Jítsu no decurso da primeira metade do século XX, nos estados da Bahia (Abreu, 1999; Almeida, 1994), São Paulo e Rio de Janeiro (Santos, 1996). Dessa maneira, ele divulgava as características da "sua" vertente da capoeira e promovia a territorialização da modalidade.

Apesar da presença nesse simpósio de um representante da outra escola de capoeira da Bahia, não há evidencias da sua manifestação quanto a esse processo de regulamentação desportiva.

Por outro lado, os representantes institucionais do desporto brasileiro também buscavam influenciar o resultado dos trabalhos empreendidos no simpósio, já cientes do conflito que se formava ao redor do tema. Após a realização da referida reunião e dos seus efeitos paralelos, Altamiro Cunha remete uma carta ao presidente da Confederação Brasileira de Pugilismo (CBP) na qual apresenta as suas escusas pela ausência no evento, bem como chama a atenção para o fato da capoeira já ser institucionalizada enquanto desporto por meio do Artigo $2^{\circ}$ dos Estatutos da confederação, referindo respeitosamente o lapso cometido pelo presidente da CBC em desconsiderar o fato, e ressaltando ser urgente regulamentá-la como "luta e não como folclore" (Cunha, 1968 setembro 5).

Os argumentos usados por Cunha, às vezes por via de um discurso questionável, refletem a idissiocrasia de todos os envolvidos no processo que manchou fatalmente os rumos desportivos da expressão. Um excerto das suas Observações para um regulamento de "Capoeira", o qual vem anexado à sua referida carta, é bastante elucidativo do que se apresenta:

LUTA E NÃO BALET - aí está um ponto crucial para que a capoeira possa se desenvolver como luta desportiva, seja a de banir, definitivamente, a pretenção da "escola baiana de COMANDAR o ritmo da luta, através de instrumentos de som, sejam de percussão do de timbre metálico (birimbaos por excelência). Quando da estrondosa vitória dos alunos de Sinhozinho sôbre os do Mestre Bimba, justificou-se êste que a sua ausência de tal prática prejudicou seus representantes a ela acostumados, mas na verdade é quase INADMISSÍVEL se querer que uma prática desportiva, dependentes do personalismo do competidor, se enquadre dentro de um ritmo musical. Já se imaginou uma competição de corridas controlada em ritmo de valsa ou tango, ou a de natação em braçadas de "balet aquático"? Isso seria a "capoeira" em ritmo "baiano" (Mesmo antes do famigerado "meio dia").

Segundo o Relatório de Atividades da Confederação Brasileira de Pugilismo (CBP) elaborado por Rogério Coutinho em 1970, os simpósios com o fim de regulamentar a Capoeira concorreram para não se conseguir "praticamente nenhum resultado". Isso reforça nossas inferências de que a personalização das discussões e a territorialização das expressões e suas estilísticas afastaram as discussões sobre a realidade motora e agonística da luta da capoeira e as centralizaram em pessoas.

Depois de muitas tentativas isoladas com vista à regulamentação desportiva, em finais de 1972, após cedências por parte das correntes em discussão, foi aprovado em plenário do Conselho Nacional dos Desporto (MEC/CND, 1973) o parecer do General Jayr Jordão Ramos (MEC/CND, 1972), que dizia respeito ao reconhecimento da Capoeira como Desporto e ao aguardo de que a CBP apresentasse as normas que iriam orientar as competições da modalidade em todo o território nacional, normas essas, efetivamente aprovadas, oficializadas e divulgadas no ano de 1973. 
Apesar da consecução desse intento, o respectivo regulamento desportivo para a capoeira, de forma caleidoscópica, foi constituído com o intuito de atender e de cooptar todas as mentalidades que reivindicavam ver contemplado o ponto de vista das distintas correntes do pensamento capoeirístico do período, fosse pela preservação, fosse pela expansão de um poder, fosse ainda pelo controle dos desenvolvimentos impingidos sobre a capoeira e de acordo com a vontade de seus principais mentores e em detrimento da objetividade presumível para um documento regulamentar.

\section{5.- Análise comparativa das propostas baiana e cariocas para o regulamento da luta da capoeira}

Com a intenção de melhor evidenciar as semelhanças e dessemelhanças entre as primeiras propostas de regulamentação da capoeira das quais temos documentação, passaremos a dispor comparativamente os tópicos mais representativos das mesmas em um quadro que nos permitirá outras discussões sobre o tema. Para isso adotamos como pressuposto a compreensão que alguns estudiosos do Jogo têm dos estruturantes das modalidades lúdicas e desportivas e da ação motora. Descrevem a lógica de funcionamento desta última como oriunda de suas regras para a realização da ação, pois tais regras determinam o tipo de relação que "os protagonistas manterão entre si, com o espaço de jogo, com o tempo e com o material de jogo, quando este existir" (Lagardera \& Lavega, 2003, p. 62).

Consideramos que o regulamento determina a estrutura do desporto, e para tal as regras poderão ser classificadas em seus aspectos formais, conforme Moreno (2004, p. 42): características e dimensões do espaço de jogo; descrição dos materiais complementares que se usam em jogo; número de jogadores que participam do jogo e forma como eles podem intervir no mesmo; forma de pontuar e como ganhar ou perder; tempo total de jogo, divisão e controle do mesmo; ritos e protocolos. Também são considerados aspectos da ação de jogo: formas de utilizar os implementos, quando existirem; formas de participação de cada jogador e relação com seus companheiros, quando existirem; formas de relacionar-se com os adversários, quando existirem; formas de utilizar o espaço de jogo; penalizações às infrações da regra.

A análise processual da capoeira, visando compreender o ritmo de sua dinâmica em estado de transformação desportiva, deve levar em conta os esboços de regras então apresentados como os primeiros passos concretos surgidos da busca pela estandardização, fenômeno que permitiria o encontro agonístico de opositores de diferentes expressões de luta sobre a luta brasileira, com as possibilidades de êxito e de fracasso equiparadas e equilibradas para todos.

Cabe ressaltar que, em relação à idéia de Annibal Burlamaqui, o Zuma, dedicamos uma atenção especial à regulamentação do espaço de jogo e à sua delimitação, bem como à caracterização dos golpes e movimentos por ele abordada em seu livro. Quanto a Bimba, além de sua elementar metodização de treinamento, podemos destacar a normatização do comportamento social de seus alunos (Almeida, 2002, p. 99), como podemos verificar in loco ${ }^{3}$. As normas eram afixadas nas paredes de sua academia e entendidas como regras deônticas (Robles, 1988, p. 163) ou código moral, mas em nada interferiam na ação motora do jogo ou da luta da capoeira desenvolvida no estado da Bahia, não podendo, portanto, ser consideradas em mesmo plano que as regras de um combate, as quais devem prever um conjunto de obrigações, direitos e proibições no campo dos atos motores e das condutas sociais.

Dos aspectos regulamentares que entendemos interferir internamente na lógica da execução do ato motor da capoeira, tanto no nível lúdico quanto no desportivo - lembrando que o segundo é simplesmente a dinamização do primeiro e, por isso, não excludente do mesmo -, podemos observar os tópicos referentes à relação dos indivíduos com o espaço da ação motora, sendo tal relação entendida minimamente com base no aspecto ou formato do referido espaço (circular ou retangular), nas subdivisões temporais previstas e ainda na questão da licitude ou ilicitude de golpes.

\footnotetext{
3 Em visita à Academia de Mestre Bimba, no Pelourinho da cidade de Salvador (BA), no ano de 2004, ciceroneados por seu filho, Mestre Nenel, pudemos constatar a existência do referido regulamento.
} 
Propriamente sobre as propostas em causa, as mesmas se desenvolvem da seguinte maneira: o Ante-Projeto do Regulamento de Capoeira, de Decânio, diretor do Departamento de Capoeira da Federação Baiana de Pugilismo (FBP), é descrito em onze páginas, dividido em onze capítulos e evidencia elementos estruturais e técnicos que se referem ao local das competições; uniformes; higiene e aparência pessoal; conduta; direitos e deveres do atleta e do mestre; conduta; direitos e deveres do árbitro, juízes e jurados; mesa diretora; início, interrupções, reinício, tempo e término (de combate); competições, categorias e classes; golpes, faltas, punições e normas de etiqueta; contagem de pontos e sentenças; exame médico e pesagem; terminologia, sinalização e ritmo.

O documento apresentado por Altamiro Nascimento Cunha, vinculado ao Boxe e delegado pelo mesmo organismo para organizar o processo de regulamentação em questão, intitulado Observações para um regulamento de "Capoeira", divide-se em sete itens, a saber: Local de Combate; Rounds; Pontagem; Golpes; Vestimenta; Restrição Policial; Luta e não Bal[I]et. Desses, apenas cinco referem-se especificamente ao contexto das lutas, já que dois constituem posições pessoais do autor sobre aspectos sociais e formas de expressividade da capoeira.

A segunda proposta carioca para a regulamentação da luta brasileira parte de um representante do estilo de Sinhozinho e denomina-se Exposição dos principais problemas encontrados nas tentativas de regulamentação da Capoeira. Redigida por Rudolf Hermanny, é composta de 11 itens, a saber: vestimenta; acessórios; local de combate; revestimento do tablado; delimitação; duração do combate; golpes válidos; golpes ilícitos; decisão; contagem de pontos; categorias dos lutadores.

Para compará-las, tratamos de sintetizá-las em cinco grandes blocos: os documentos; os elementos inerentes à competição; as atitudes dos atletas; as obrigações dos árbitros; a abrangência dos golpes (Tabela 1). A tabela a seguir é, portanto, uma síntese das três discussões que visavam nortear a regulamentação desportiva da luta da capoeira, elaboradas entre os anos de 1968 para apreciação no I Simpósio de Capoeira, realizado no estado do Rio de Janeiro.

Essas propostas originaram-se dos dois principais centros de prática da capoeira na época Rio de Janeiro e Bahia. Esses estados irradiam os três principais estilos desenvolvidos no Brasil, o pragmático, o regional baiano e o Angola. Embora haja referências históricas de outras formas estilísticas da luta nacional, elas nunca conseguiram se afirmar socialmente.

A caracterização da capoeira, representada pelos documentos analisados, varia conforme a percepção do objeto de cada proponente, sendo a impregnação de aspectos rituais e lúdicos um caráter da sugestão baiana para a sua afirmação enquanto desporto, o que não se coaduna em exatidão com esse conceito, que inclui o regulamento preciso da competição, a institucionalização, a espetacularidade, conforme Parlebas (2001, p. 105), e a identificação com processos de produção e consumo, conforme Mandell (1986, p. 271).

No que toca aos envolvidos no processo de regulamentação da luta desportiva da capoeira e às concepções de desporto da época, podemos mencionar a própria categorização que a CBP atribuiu em seus estatutos à capoeira e ao Jiu-Jítsu: expressões pró-desporto, ou seja, em vias de serem enquadradas na categoria de desporto de luta, sendo a regulamentação desportiva uma das exigências para tal.

Mais recentemente e de forma a reforçar a idéia anterior, Parlebas (2001, p. 276) entende que a luta poderá ser um jogo desportivo e um desporto se institucionalizada, no que concordamos sumariamente. Entende também que, se a prática em causa dá-se de maneira aberta, flexível e com regras mutantes, poderia ser compreendida como um quase jogo, ou seja, uma daquelas expressões que chamamos de brincadeira. Transpostas tais idéias para o contexto histórico da capoeira, desde o seu surgimento até os nossos dias, na perspectiva da teoria das múltiplas transformações de Araújo (2007, p. 199), entendemos ser perfeitamente consequente a abordagem que ora adotamos para a categorização dos documentos em pauta.

Os elementos terminológicos evidenciados nos documentos das propostas apresentam diferenças claras, sendo os vocábulos usados pelos representantes cariocas mais compatíveis com as práticas de luta do Judô, Boxe e Luta Livre, destacando-se termos como ring, rounds, tatame, 
tablado, e não se considerando os vocábulos usuais entre os praticantes de capoeira do Rio de Janeiro e da Bahia de então.

Tabela 1

Análise das três propostas para a regulamentação da capoeira (1969)

\begin{tabular}{|c|c|c|c|}
\hline $\begin{array}{l}\text { Blocos / Origem } \\
\text { da proposta }\end{array}$ & $\begin{array}{l}\text { Federação Bahiana de } \\
\text { Pugilismo - Bahia }\end{array}$ & $\begin{array}{l}\text { Confederação Brasileira de } \\
\text { Pugilismo - Rio de Janeiro }\end{array}$ & $\begin{array}{c}\text { Capoeira pragmática Sinhozinho - } \\
\text { Rio de Janeiro }\end{array}$ \\
\hline \multicolumn{4}{|l|}{ Do Regulamento } \\
\hline Terminologia & $\begin{array}{l}\text { Apresenta termos, mas não } \\
\text { discute significados. }\end{array}$ & Não apresenta. & Não apresenta. \\
\hline Caracterização & $\begin{array}{l}\text { Artística, jogo desportivo e } \\
\text { ritual. }\end{array}$ & Luta desportiva. & Luta desportiva. \\
\hline \multicolumn{4}{|l|}{ Da Competição } \\
\hline Local de competição & Terreiro e roda. & Ringue (tablado). & Ringue ou solo. \\
\hline Vestimenta & $\begin{array}{l}\text { Calça e camisa, sem sapato, } \\
\text { sem protetores. }\end{array}$ & $\begin{array}{l}\text { Camisa sem golas e mangas, } \\
\text { calça comprida, sapatos de } \\
\text { lona, solado de borracha. }\end{array}$ & $\begin{array}{l}\text { Calção de luta livre, sapato de couro } \\
\text { acolchoado. Uso de protetores. }\end{array}$ \\
\hline Competições & $\begin{array}{l}\text { Duplas ou ritmo, e individual } \\
\text { ou luta. }\end{array}$ & Luta. & Luta. \\
\hline Categorias & Define. & Define. & Define. \\
\hline Ritmo & $\begin{array}{l}\text { São Bento Grande - individual } \\
\text { e duplas a escolher. }\end{array}$ & Proíbe. & Não refere. \\
\hline Exame médico & Define. & Não refere. & Não refere. \\
\hline Pesagem & Define. & Não refere. & Não refere. \\
\hline \multicolumn{4}{|l|}{ Do Atleta } \\
\hline Conduta do atleta & $\begin{array}{l}\text { Define regras de } \\
\text { comportamento e } \\
\text { responsabiliza o mestre. }\end{array}$ & Não refere & Não refere. \\
\hline Punições & $\begin{array}{l}\text { De antijogo e violação das } \\
\text { regras. }\end{array}$ & Para violação das regras. & Para violação das regras. \\
\hline \multicolumn{4}{|l|}{ Da Arbitragem } \\
\hline Conduta do árbitro & $\begin{array}{l}\text { Define por competências e } \\
\text { gestual de jogo. }\end{array}$ & Não define. & Não define. \\
\hline Mesa diretora & Define competências. & Não refere. & Não refere. \\
\hline Tempo de luta & $\begin{array}{l}\text { Define ritual de início e final } \\
\text { de luta, duração de 3' por } \\
\text { volta, 1' de intervalo. Não } \\
\text { define o número de voltas. }\end{array}$ & $\begin{array}{l}\text { De } 3 \text { a } 12 \text { ou } 15 \text { rounds, de } 3 \text { ' a } \\
5 \text { ', intervalos de } 1 \text { ' a } 2 \text { ' entre } \\
\text { eles. }\end{array}$ & $\begin{array}{l}\text { Amadores: } 3 \text { rounds; profissionais: } 6 \\
\text { rounds ou mais; 3' e 2' de intervalos. }\end{array}$ \\
\hline Pontuação & $\begin{array}{l}\text { Das duplas: jogo ou estilo, } \\
\text { efeitos coreográficos, ritmo } \\
\text { musical, riqueza de } \\
\text { movimentos, passes, golpes, } \\
\text { sequência, perfeição técnica, } \\
\text { entrosamento entre atletas, } \\
\text { lisura e ética. } \\
\text { Do individual: por avaliação da } \\
\text { mímica de golpes não } \\
\text { finalizados, por quedas } \\
\text { finalizadas e encurralamentos } \\
\text { de } 10 " \text { a } 20 " .\end{array}$ & $\begin{array}{l}\text { Súmula de referentes a ataque, } \\
\text { defesa, eficiência, quedas, } \\
\text { fugas, nocaute e } \\
\text { desclassificação. }\end{array}$ & $\begin{array}{l}\text { Como no Boxe, de acordo com os } \\
\text { jurados e por súmula de itens } \\
\text { referentes a ataque, defesa, técnica e } \\
\text { eficiência. }\end{array}$ \\
\hline \multicolumn{4}{|l|}{ Dos Golpes } \\
\hline Golpes permitidos & $\begin{array}{l}\text { Não refere, considera todos os } \\
\text { movimentos como golpes. }\end{array}$ & $\begin{array}{l}\text { Não refere, mas aponta a } \\
\text { necessidade de definição. }\end{array}$ & $\begin{array}{l}\text { Golpes de percussão e } \\
\text { desequilibrantes desferidos com } \\
\text { braços, pernas e cabeça. }\end{array}$ \\
\hline Golpes proibidos & $\begin{array}{l}\text { Ataque aos olhos, ouvidos, } \\
\text { boca, genitais, quedas com } \\
\text { projeção, bofetadas, beliscões, } \\
\text { torções e estrangulamentos. }\end{array}$ & $\begin{array}{l}\text { Soco, cutelara [cutilada], } \\
\text { pisadas, ponta-pé [sic] } \\
\text { (quando caído no solo). }\end{array}$ & $\begin{array}{l}\text { Os desferidos com o dorso da mão, } \\
\text { cutiladas, joelhadas, cotoveladas na } \\
\text { nuca, na região lombar, genitais, } \\
\text { mordidas, puxão de cabelo ou } \\
\text { orelhas, dedos nos olhos, } \\
\text { agarramentos em pé ou no solo por } \\
\text { mais de 10'. }\end{array}$ \\
\hline
\end{tabular}


Contrariamente, a proposta baiana apresenta-se repleta de expressões muito particulares e usuais no âmbito capoeirístico da Bahia, as quais viriam a se estabelecer efetivamente nesse contexto, destacando-se termos como terreiro, roda, volta, gingar, mestre. Ainda nesse tópico, verificamos outra oposição patente entre as propostas, representada no documento baiano pelas características que enquadravam a luta brasileira como expressividade artística, ritual e lúdicodesportiva, esta última mais próxima das características gímnicas de modalidades como a ginástica artística e a ginástica rítmica, ao passo que as propostas cariocas apenas destacavam o caráter agonístico da modalidade, sua expressão essencial de luta desportiva propriamente dita, à semelhança de outras expressões congêneres.

A formação dos indivíduos que realizaram as propostas de regulamentação da capoeira é marcadamente exposta nos argumentos que cada um deles utiliza a respeito da desportivização da modalidade. Assim como no subitem vestimenta, podemos observar a índole lúdica da proposta da Bahia e suas preocupações rituais ao manter o homem de pés descalços, em contato com a terra, além de não permitir protetores para os atletas, já que o contato físico entre eles também não era permitido. Por outro lado, os cariocas, em virtude de suas experiências com outras modalidades de luta, entendiam como normal e necessária a utilização de vestimenta adequada e que não causasse danos aos lutadores. Uma das propostas cariocas contemplava ainda o uso de protetores.

A tentativa de manter a índole lúdica de uma pretensa capoeira desportiva é ressaltada pelo mentor baiano na proposta de realização de competições de ritmo, por exemplo, apesar de concordar com os seus interlocutores cariocas quanto à necessidade da definição de categorias de lutadores, o que mostra a dubiedade de seu pensamento entre o que é jogo e desporto, bem como a sua intenção de preservar o que reconhecia como aspectos pertinentes e inquestionáveis da capoeira. Um desses aspectos está claramente assinalado pelo subitem ritmo, rechaçado por Altamiro Cunha e não referido por Hermanny, demonstrando este último um titubear entre o rigor da regra desportiva e a permissividade da regra lúdica.

No subitem exame médico, Decânio aponta de antemão a sua necessidade, demonstrando assim esmero com uma proposta de regulamentação o mais abrangente possível, preocupação igualmente evidenciada nos subitens pesagem, conduta do árbitro, mesa diretora e conduta do atleta.

Em relação às punições, aspecto altamente relevante de um regulamento desportivo, especialmente por tratar-se de um confronto corporal, Decânio ressalta duas condições: o antijogo e a violação das regras, esta também contemplada nas propostas cariocas. Chama-nos também a atenção a preocupação do mestre baiano em ter atitudes pedagógicas em relação não só aos atletas mas também aos seus mestres, aos quais eram dirigidas formas de punição por seu próprio comportamento, assim como pelo mau comportamento de seu atleta.

Entre os aspectos por nós entendidos como os mais relevantes para essa primeira idéia de regulamento da capoeira, encontram-se os subitens tempo de luta, pontuação, golpes permitidos e golpes proibidos, todos considerados pelos três autores, mas com posições diferentes entre si.

No que se refere ao tempo de luta, os três consultados são unânimes em sugerir pelo menos três minutos, podendo chegar a cinco minutos, segundo Cunha. Os intervalos entre um round ou volta são variáveis entre todos, indo de um a dois minutos, assim como varia também o número de rounds ou voltas. Enquanto Decânio nada refere sobre esse tópico, Cunha aponta três, doze ou quinze rounds e Hermanny torna a idéia um pouco mais complexa, sugerindo três rounds para amadores e seis para profissionais, antevendo outra dinamização para o então desejado desporto capoeira, ainda não pensada ou, ao menos, não revelada entre os seus aficionados: a profissionalização do atleta.

O subitem pontuação também guarda severas diferenças de pensamento entre as propostas apresentadas: a baiana contempla os aspectos rituais, artísticos, melódicos, rítmicos, entre outros, ao passo que as cariocas detêm-se mais nos aspectos técnicos da modalidade em desportivização. Decânio ainda pensa em produzir súmulas para as duplas e para cada atleta, nas quais ressalta o intervalo de pontuação entre zero e dez tentos por golpes não finalizados, quedas finalizadas e encurralamentos. 
Todavia, em um subitem que também merecia mais atenção dos que se propunham a delimitar as regras para o desporto capoeira, Decânio insinua certa liberdade criativa para os atletas, entendendo serem todos os movimentos golpes de capoeira, embora aponte os que deveriam ser proibidos. Já Cunha destaca a necessidade da definição dos golpes permitidos e proibidos, referindo apenas os que entendia deverem ser proibidos. Já Hermanny menciona de forma geral os golpes que a seu ver deveriam ser permitidos ou proibidos.

Dos subitens que apontamos aqui como os mais relevantes para uma discussão inicial sobre o regulamento de uma modalidade desportiva de luta, observamos uma tendência geral para a discussão dos mesmos, o que demonstra um norteamento funcional para o sucesso dessa empreitada. Entretanto, quando atentamos para cada conteúdo do discurso dos envolvidos nessa tarefa de pensar o primeiro regulamento de capoeira, percebemos profundas discrepâncias de idéias, as quais surgem das próprias concepções sobre a modalidade e perpetuam a discórdia a respeito do assunto.

É óbvia aos olhos de qualquer leitor a inspiração para a construção dos anteprojetos em análise, de regulamentos derivados de regulamentos de outras modalidades de luta circulantes no Brasil, dando-se o primeiro passo para uma discussão da qual supostamente surgiria um regulamento mais próximo do ideal, amalgamado pelas idéias particulares que seus mentores traziam. Contudo, aspectos outros que não condicionavam diretamente a efetivação do combate de capoeira foram também apresentados em projeto regulamentar, sendo eles externos à ação motora e nos permitindo outra forma de classificação desportiva sobre os tipos de capoeira, os quais estavam implícitos no ideário dos envolvidos. Apesar de esses entendimentos serem aceitáveis para aquele período, careciam de regulamentos particulares conforme a sua especialidade e suas lógicas internas.

Não há dúvida de que a proposta de Decânio se revela mais abrangente; todavia, é também aquela que mais se desvia da possibilidade de um regramento eficaz da capoeira enquanto manifestação de luta desportiva, apesar de se verem nas entrelinhas do documento em análise aspectos inerentes aos desportos de combate no contexto das suas características artísticas e lúdicas.

Tomando por apoio a Ciência da Praxiologia Motriz (Lagardera \& Lavega, 2003, p. 67) e o conceito de lógica interna do Jogo/Desporto, que vigora sobre as formas de relação dos protagonistas da ação motora entre si, deles com o espaço, com o tempo e com os materiais (quando existirem), concluímos que a forma de relação dos capoeiristas no momento da luta é definida pela contracomunicação, ou seja, por oposição entre protagonistas, o que afeta diretamente o desenvolvimento da ação, já que um sai vencedor e o outro é derrotado. Tal forma de comunicação é essencialmente diferente das estabelecidas entre protagonistas de um espetáculo artístico ou ritual.

A análise comparativa das propostas cariocas e baiana para a regulamentação da capoeira, surgidas no I Simpósio de Capoeira (1968), revela existirem em seus conteúdos abordagens bastantes generalizadas sobre o contexto regulamentar da capoeira e algumas específicas sobre o seu texto - a luta desportiva -, sendo a proposta baiana a mais extensa, ao passo que as cariocas se apresentam com igual densidade entre si e bastante mais reduzidas em comparação com a baiana. Consideramos serem abordagens contextuais (ou da lógica externa) das propostas em pauta os tópicos relativos a: terminologia, vestimenta, ritmo, exame médico, pesagem, conduta do atleta, conduta do árbitro, e mesa diretora. Igualmente consideramos serem tópicos relativos ao texto (lógica interna da luta desportiva) as seguintes referências encontradas nas propostas: caracterização, punições, golpes permitidos e golpes proibidos e competições (tipo de relação existente entre os protagonistas da ação motora), local de competição (relação dos protagonistas com o espaço de jogo), pontuação (relação dos protagonistas com o tempo, início e final da ação motora, formas de adquirir pontos no combate).

Especificamente no caso da luta, a competitividade é estabelecida pelo objetivo da ação motriz - o espaço branco ${ }^{4}$-, ou seja, o corpo do outro, que é o alvo a atingir por contato direto, por

4 Parlebas (2001) relacionou as distâncias de oposição entre diversas modalidades atribuindo categorias às mesmas: os duelos de distância quase nula (Luta Canária, Greco-Romana, Livre Olímpica e Judô), os de distância média (Florete, 
meio de assaltos realizados a distância reduzida (Parlebas, 2001, p. 150). Apenas as propostas de Cunha e Hermanny contemplavam a perspectiva da regulamentação da luta desportiva, enquanto Decânio desprezava essa configuração em favor das componentes artísticas e lúdicas da capoeira, inviabilizando a sua expressão agonística.

Na Figura 1 vemos representadas pela proposta de Decânio duas formas de expressão da capoeira e uma forma de expressão mágica atribuída à sua existência. Contudo, a luta desportiva em si não é contemplada, ao contrário do que ocorre nas propostas de Cunha e Hermanny. Paradoxalmente, a maior abrangência da primeira proposta não garante o objetivo de regulamentação da capoeira enquanto ação de combate - o desporto de combate tem por característica primordial o contato físico e pode utilizar implementos ou não -, estancando sua tarefa no aspecto lúdico do jogo desportivo sem contato físico, o qual, estruturalmente, não permite nem necessita de regulamentação rígida, pois o jogo é uma ação de participação voluntária, livre e com objetivos de recreação em si mesmo. No que toca ao quê artístico da expressão, ele é representado na proposta baiana por previsões de pontuação para quesitos tais como estilo, riqueza de movimentos, passes, sequência, perfeição técnica, entrosamento entre atletas, avaliação da mímica, golpes não finalizados etc.

\section{Figura 1}

Abrangências das propostas e anteprojeto de regulamentação da capoeira.

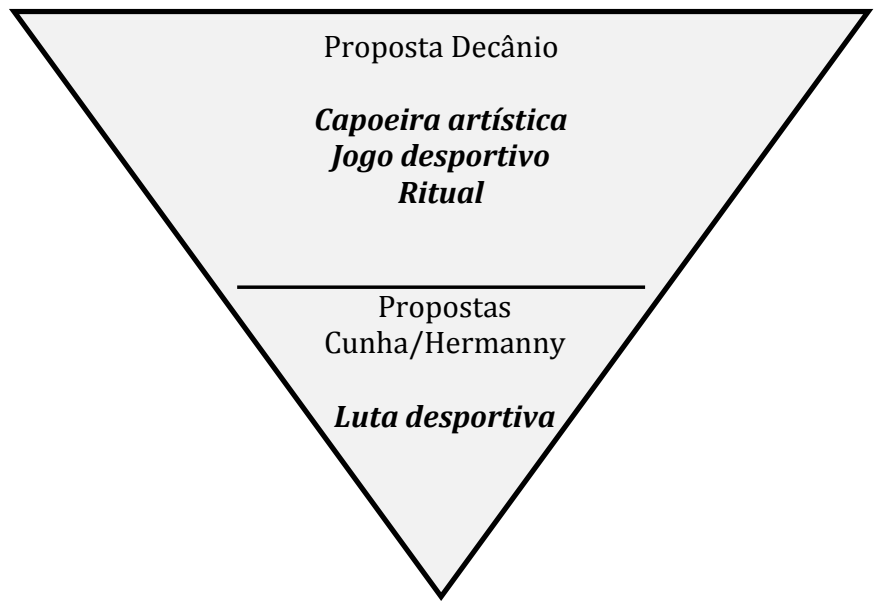

Entendemos ser essa lógica de relação entre os indivíduos, o espaço e o tempo diferenciada da lógica da luta, o que por si só exigiria uma regulamentação à parte e mais compacta no que diz respeito a cada termo que se busca avaliar. Acreditamos que o aspecto melódico, também contemplado pela proposta de Decânio, seja o elo entre as tendências artísticas e rituais imaginadas para a regulamentação de um combate que necessariamente não deveria ocorrer. Da mesma forma, como tal proposta escrita parte de outra ou outras tendências, confeccionadas para outros desportos de combate, inferimos que a diferenciação que os indivíduos envolvidos com a capoeira julgavam ser necessária em relação a outras lutas foi reforçada pela inclusão da música e do ritual nesse anteprojeto de regulamento.

Como já foi mencionado, certos aspectos abordados nas propostas de regulamento para a luta da capoeira em nada interferem direta ou indiretamente na ação motora e na qualidade do desempenho do indivíduo que executa o ato motriz. São exemplos disso a melodia e o ritual, atribuídos à capoeira como elementos de sua composição inicial.

0 aspecto melódico é particularmente rechaçado na proposta de Cunha via proibição em regulamento, mas não é referido na proposta de Hermanny, e nenhuma delas refere o componente 
ritual como tópico de relevância para a previsão em regulamento da luta capoeira. Entretanto, nos dias que correm temos conhecimento de lutas autóctones que fazem presentes em seus encontros de competição desportiva elementos rituais característicos e originais, tais como o Sumô e o Muaythai. Esses elementos fazem parte do espetáculo, mas não interferem no andamento da ação motora nem são avaliados em sua qualidade, o que seria incoerente. Do mesmo modo, seria absurdo imbuir a capoeira de um caráter religioso ao qual nem todo adepto é afeito.

O segundo bloco, o mais específico para o contexto da capoeira, é aquele que mais apresenta diferenças entre as propostas, ressaltando-se a oposição quer quanto à definição da tipologia do espaço de desenvolvimento do combate, quer quanto à especificidade do combate. A proposta baiana para aquele primeiro item indica a sua realização num terreiro - "O terreiro deverá ter o piso de madeira, chão batido, ladrilhado, cimentado, plástico, borracha ou similares." -, espaço com características específicas e bem distintas daquelas apresentadas pelos representantes cariocas, que o definem com as mesmas características espaciais do Judô ou do Boxe, seja quanto aos materiais utilizados, seja quanto às suas dimensões. Outro elemento bem distinto entre as propostas sobressai quando se comparam as formas de competição capoeirística, sendo uma essencialmente agonística e de combate expresso individualmente e a outra, igualmente agonística, mas essencialmente lúdica ou gímnica, expressa em dupla ou individualmente e acompanhada de estruturas rítmicas.

Nesse tópico, também verificamos um elemento comum entre as propostas quando tratam das categorias dos competidores. Há ainda dois aspectos que apenas são tratados no documento da Bahia, os quais, curiosamente, não são particulares da capoeira, mas genéricos às outras lutas aludidas.

O bloco três apenas nos apresenta dois elementos, um deles comum entre as propostas e no qual são descritas as punições para as violações das regras e também do antijogo, sendo apenas manifestas na proposta baiana as regras de conduta dirigidas aos atletas e a consequente responsabilização de seus mestres.

O seguinte bloco é aquele que nos três primeiros itens apresenta uniformidade de idéias, de modo que as proposições se permitem realizar a tarefa a que se destinam, ou seja, encontrar as convergências possíveis entre propostas muitas vezes díspares. Entretanto, é no item referente à contagem de pontos que percebemos as principais características que distinguem as propostas em estudo, evidenciando-se os elementos de jogo e de luta que desde as primeiras linhas dos respectivos documentos se fazem notar: as características referidas na proposta baiana foram "efeitos coreográficos; ritmo musical; riqueza de movimentos; sequência; perfeição técnica; entrosamento"; as propostas cariocas referem como características de avaliação "o ataque; a defesa; eficiência; quedas; fugas; nocaute". Da proposta baiana é-nos clara a perspectiva lúdica e os seus elementos de avaliação, que mais aproximam a capoeira das avaliações de competições gímnico-desportivas do que das de luta, não deixando por isso de se poder enquadrar num espectro de cariz competitivo. Por outro lado, as propostas cariocas se pautam pelos modelos de avaliação competitiva da maioria das lutas desportivizadas até então conhecidas.

O último bloco de análise das propostas regulamentares para a capoeira trata especificamente dos elementos essenciais de uma luta qualquer, que no Quadro 1 referem-se aos golpes da luta brasileira, distinguidos em golpes permitidos e proibidos, sendo as orientações expressas por aqueles efetivos praticantes da luta em estudo mais coerentes e mais objetivas do que aquelas colocadas pelo assessor confederativo (Decânio). Ainda considerando as propostas, constatamos que as derivadas do dirigente baiano não parecem coadunar-se com os critérios de avaliação propostos, visto se concentrarem em elementos de natureza ginástica, e não nos desportivos de luta propriamente dita. Desse modo, as propostas cariocas revelam-se mais orientadas para os aspectos dos combates de luta.

\section{6.- Conclusões}

A análise praxiológica das três propostas de regulamentação desportiva da capoeira nos leva a concluir que a baiana, apesar de mais extensa, é a que refere mais elementos da lógica externa da luta e caracteriza-se por sua índole lúdica, artística e ritualística. Por sua vez, as 
propostas cariocas apresentam mais elementos da lógica interna da capoeira, aproximando-se mais do conceito e do formato de um regulamento desportivo de luta. Destas, é a proposta oriunda da Confederação Brasileira de Pugilismo (CBP) a mais objetiva, o que nos leva a inferir que a vivência dos seus autores no ambiente especializado em lutas estrangeiras já desenvolvidas no Brasil, pode ter favorecido o raciocínio para a resolução do problema em causa.

A evidente falta de consenso entre Rio de Janeiro e Bahia na elaboração das propostas de regulamento foi impeditiva para o atendimento dos interesses dos dois polos capoeiristas. A análise documental realizada demonstra que fatores de ordem territorial (Rio de Janeiro e Bahia), estilística (Regional, Angola, Sinhozinho) e personalística (Bimba, Pastinha, Altamiro Cunha) tiveram maior protagonismo nas discussões do que propriamente as considerações relativas à regulamentação da luta da capoeira.

Desta feita, o esforço dos redatores das propostas para o regulamento de capoeira, bem como da organização do Simpósio de 1968, foi ofuscado pelas idiossincrasias dos representantes baianos e cariocas protagonistas da discussão. Ressaltamos ainda que, mesmo diante do contexto político brasileiro na época, e contrariamente aos Estatutos da Confederação Brasileira de Pugilismo (CBP) que aludiam à sua exclusividade na confecção de regulamentos das modalidades a ela ligadas, o simpósio foi aberto a todos os interessados na discussão, chamados a debater democraticamente sobre essa modalidade, na qual eram considerados experts.

Pelo exposto, concluímos não estarem reunidas naquele momento as condições para a regulamentação desportiva da luta brasileira, dada a maneira de ver dos intervenientes nessa discussão, por apenas entenderem aquela capoeira desenvolvida a partir da sua óptica, do seu estilo e do seu território, o que os impossibilitava de perceber as suas possibilidades de expressividade por meio de características regulamentares inerentes a outras modalidades de luta já desenvolvidas nesse aspecto.

\section{Referências}

Albarello, L. Digneffe, F., Hiernaux, J-P., Maroy, C., Ruquoy, D., \& Saint-Jorges, P. (1997). Prática e métodos de investigação em Ciências Sociais. (L. Baptista, trad.) Lisboa, Gradativa. (Obra original publicada em 1995).

Abreu, F.J. (1999). Bimba é Bamba: A Capoeira no Ringue. Salvador: Instituto Jair Moura.

Aleixo, M. (1921). A arte da defesa pessoal. Revista da Semana, 25.

Almeida, R.C. (2002). A saga do mestre Bimba. Salvador: Ginga Associação de Capoeira.

Araújo, P.C. (1997). Abordagens sócio-antropológicas da luta/jogo da Capoeira. Maia: Instituto Superior da Maia.

Baztán, A. A. (1995). Etnografía. In Baztán, A. (Org.), Etnografía: metodología cualitativa en la investigación sociocultural (pp. 3-19). Barcelona: Boixareu.

Burlamaqui, A. (1928). Gymnastica Nacional (capoeiragem) methodizada e regrada. Rio de Janeiro.

Capoeira está em crise? É o que dizem. Mestre Bimba abandona o Simpósio. (1969, 15 novembro). Diário Popular. Primeiro Caderno.

Capoeiristas baianos retiram-se de congresso no Rio de Janeiro. (1969, 17 novembro). A Tarde. Caderno Folclorando.

Cohen, L. \& Manion, L. (2002). Métodos de investigación educativa. (2 $2^{\underline{a}}$ ed.). (F. A. López, trad.) Madrid: Editorial La Muralla. (Obra original publicada em 1989).

Confederação Brasileira de Pugilismo. (1941). Estatuto da Confederação Brasileira de Pugilismo. Rio de Janeiro.

Confederação Brasileira de Pugilismo. (1968). Simpósio de Capoeira - Convite. Ofício CBP 1.542/68. Rio de Janeiro, 16 de agosto de 1968.

Confederação Brasileira de Pugilismo. (n. d.). Relatório de Atividades, por Rogério Coutinho. Rio de Janeiro.

Conselho Nacional de Desportos. (1963). Ata da 1a sessão ordinária. Rio de Janeiro, 16 de janeiro 1963.

Cunha, A. N. (1968). Observações para um regulamento de capoeira. Rio de Janeiro. 
Elias, N. (1992). Ensaio sobre o desporto e a violência. In N. Elias e E. Dunning, A busca da excitação. (pp. 23-256). (L. Konder, trad.) Rio de Janeiro: Guanabara Koogan. (Obra original publicada em 1985).

Federação Baiana de Pugilismo. (n. d.). Ante-Projeto do Regulamento de Capoeira. Salvador.

Franco, M.L.P.B. (2003). Análise de Conteúdo. Brasília: Editora Plano.

Hammersley, M. \& Atkinson, P. (1994). Etnografia: métodos de investigación. (M. A. Otazu, trad.). Barcelona: Paidós Ibérica. (Obra original publicada em 1983).

Hermanny, R. (n. d.). Principais problemas encontrados nas tentativas de regulamentação da capoeira). Rio de Janeiro.

Jaqueira, A. R. (2010). Fundamentos histórico-sociais do processo de desportivização e de regulamentação desportiva da Capoeira. Tese doutoramento, Faculdade de Ciências do Desporto e Educação Física, Universidade de Coimbra, Coimbra, Portugal.

Lagardera, P. \& Lavega, P. (2003). Introducción a la Praxiologia Motriz. Barcelona: Editorial Paidotribo.

Lakatos, E.M. \& Marconi, M.A. (1992). Metodologia científica. São Paulo: Atlas.

Lalande, A. (1993). Letures sur la Philosophie des Sciences [em linha]. Paris: PUF. Filoinfo: Filosofia da Ciência e da Técnica Web site. Acedido em junho 1, 2012, em http://filoinfo.bemvindo.net/node/557. (Original publicado em 1926).

Lardies, M. (1964). Coletânea de Leis e Regulamentos dos Desportos. (5ª ed.). Porto Alegre: Oficinas Gráficas da Imprensa Oficial.

Mandell, R. D. (1986). Historia cultural del deporte. Barcelona: Edicions Bellaterra.

Marinho, I. P. (1981). A ginástica brasileira. Brasília: Transbrasil.

Ministério da Educação e Cultura / Conselho Nacional de Desportos. (1972). Parecer sobre a Capoeira-Desporto. Rio de Janeiro, 26 de julho 1972.

Ministério da Educação e Cultura / Conselho Nacional de Desportos. (1973). Ata da 1a sessão ordinária. Rio de Janeiro, 1973.

Moreno, J. H. (2005). Fundamentos del deporte: análisis de las estruturas del juego desportivo. 3a edición. Barcelona: Inde Publicaciones.

Parlebas, P. (2001). Juegos, deporte y sociedad: léxico de Praxiología Motriz. (Fernando G. D. C. Román, trad.). Barcelona: Editorial Paidotribo. (Obra original publicada em 1998)

Rego, W. (1968). A Capoeira Angola: ensaio sócio-etnográfico. Salvador: Editora Itapoã.

Robles, G. M. (1988). Las Reglas del Derecho y las Reglas de los Juegos: ensayo de teoria analítica del derecho. México: Universidad Nacional Autónoma do México.

Santos, E. M. (1996). Conversando sobre Capoeira... São Paulo: o autor.

\section{Datos biográficos de los autores}

Ana Rosa Jaqueira é professora auxiliar na Faculdade de Ciências do Desporto e Educação Física da Universidade de Coimbra. Doutora em Ciências da Atividade Física, tese denominada Fundamentos históricosociais do processo de desportivização e da regulamentação desportiva da Capoeira (2010). Mestre em Educação Física, na área da Psicologia do Desporto: dissertação denominada Análise do comportamento agressivo na Capoeira sob a concepção dos mestres (1999). Co-autora do livro Do jogo das imagens às imagens do jogo: nuances de interpretação iconográfica sobre a Capoeira (2008); dentre outros artigos sobre a temática da luta brasileira. E-mail: anarosa@fcdef.uc.pt

Paulo Coêlho de Araújo é professor associado na Faculdade de Ciências do Desporto e Educação Física da Universidade de Coimbra. Doutor em Ciências da Atividade Física, tese denominada Abordagens sócioantropológicas da luta/jogo da Capoeira (2005). Autor dos livros Abordagens sócio-antropológicas da luta/jogo da Capoeira (2007); Capoeira: um nome, uma origem (2004); Capoeira, novos estudos (2005); Do jogo das imagens às imagens do jogo: nuances de interpretação iconográfica sobre a Capoeira (2008); dentre outros artigos sobre a temática da luta brasileira. Docente do bloco "Capoeira" da disciplina dos "Estudos Práticos" da FCDEF-UC. E-mail: pcoelho@fcdef.uc.pt 